\title{
Synthèse
}

\section{La multifonctionnalité des prairies en France : I. Les fonctions de production}

\section{Christian Huyghe}

Unité de génétique et d'amélioration des plantes fourragères,

Institut national de la recherche agronomique

(Inra),

BP 6,

86600 Lusignan,

France

<christian.huyghe@|usignan.inra.fr>

\begin{abstract}
Résumé
L'analyse de la multifonctionnalité des prairies requiert de resituer ces surfaces dans la filière de production complexe à laquelle elles contribuent. Dans une première partie, cet article présente les évolutions en France des surfaces fourragères et prairiales et des productions herbivores au cours des dernières décennies avec un éclairage sur les changements majeurs survenus durant les deux derniers siècles. L'augmentation des cultures fourragères annuelles, la forte diminution des prairies artificielles et la réduction des surfaces en prairies permanentes sont les changements majeurs des dernières décennies. Outre la constante réduction des effectifs ovins et bovins, la réduction du cheptel laitier et l'augmentation du cheptel allaitant ont entraîné des changements de types de prairies, de modes de conduite et un déplacement accompagné d'une spécialisation des régions de production. L'analyse systémique de la filière en France conduit à identifier trois fonctions majeures aux yeux des acteurs. Cet article se concentre sur les fonctions de production. La première d'entre elles est la contribution à la performance économique des exploitations d'élevage et plus particulièrement à la recherche d'un équilibre entre revenu et travail pour les éleveurs. Cela constitue une extension de la fonction de production de biomasse traditionnellement assignée aux prairies. La seconde fonction est la contribution des prairies à la qualité des produits animaux, gage de leur accès aux marchés et d'une réponse satisfaisante aux attentes des consommateurs. Cette qualité recouvre la composition nutritionnelle, le goût et l'image. L'analyse des fonctions de production souligne l'importante contribution des prairies d'une part à la performance économique des exploitations d'élevage, avec la question croissante liée au travail, et, d'autre part, à la qualité des produits animaux.
\end{abstract}

Mots clés : élevage ; herbivore ; qualité ; prairie.

Thèmes : économie et développement rural ; productions animales ; productions végétales.

\section{Abstract \\ Multi-function grasslands in France: I. Production functions}

Analysis of grassland multi-functionality requires that the whole supply chain which grasslands belong to be taken into account. In the first section this paper presents changes in acreage of grasslands and forage crops as well as in the number of herbivore heads which occurred in France over the last two centuries with a focus on the last decades. An increased acreage of annual forage crops, a strong decline of perennial forage legumes and a reduction in permanent grasslands are the main changes which occurred over the last decades. Numbers of sheep and dairy cows decreased while the number of suckling cows increased leading to modifications in the type of grasslands and forage crops and in their management regimes. It also induced changes in the location of the animal production and a specialisation of the territories. Using systemic analysis of the supply chain in France, three functions were identified as being major for all stakeholders. The paper will focus on the production functions. The first of them is the contribution of animal farms to economic performance, and more specifically to the balance between farmer income and workload. This function is a continuation of the biomass production function which was traditionally assigned to grasslands. The second function is the contribution to quality of animal products which secures their access to markets and a satisfactory answer to consumer expectations. Quality includes nutritional composition, taste and image. This analysis underlines the contribution of grasslands to farm economic

Tirés à part : C. Huyghe 
performance on the one hand with an increasing concern paid to workload. On the other hand, their implication in product quality emphasizes the need to take them into account in numerous production specifications.

Key words: animal husbandry; herbivores; prairies; product quality.

Subjects: animal productions; economy and rural development; vegetal productions.

\section{Les prairies}

\section{dans le contexte de la filière de production}

Les prairies et cultures fourragères se situent au cour d'une filière de production complexe (figure 1), impliquant de nombreux acteurs économiques (Huyghe et al., 2005).

Par les caractéristiques biologiques des espèces qui les composent, l'importance des surfaces concernées et la complexité de cette filière de production, les prairies et cultures fourragères assurent différentes fonctions au service de l'agriculture et de l'ensemble de la société. Ces fonctions se regroupent en trois ensembles majeurs.
Le premier, incontestablement central et historique, est leur contribution à la fourniture de fourrages, matière première constituant la ration de base des herbivores domestiques. Au cours des siècles passés, ces herbivores ont apporté aux fermes leur force de traction. Aujourd'hui, ce sont les productions animales, lait et viande, qui sont valorisées. Par cette fonction de production alimentaire, les prairies et cultures fourragères contribuent à la performance économique des exploitations d'élevage.

Le deuxième ensemble concerne le rôle de la prairie dans l'élaboration de la qualité des produits animaux issus des élevages herbivores et de l'industrie agroalimentaire associée. Cela permet aux produits de répondre aux attentes des consommateurs, élément important dans la définition du prix de ces produits. On

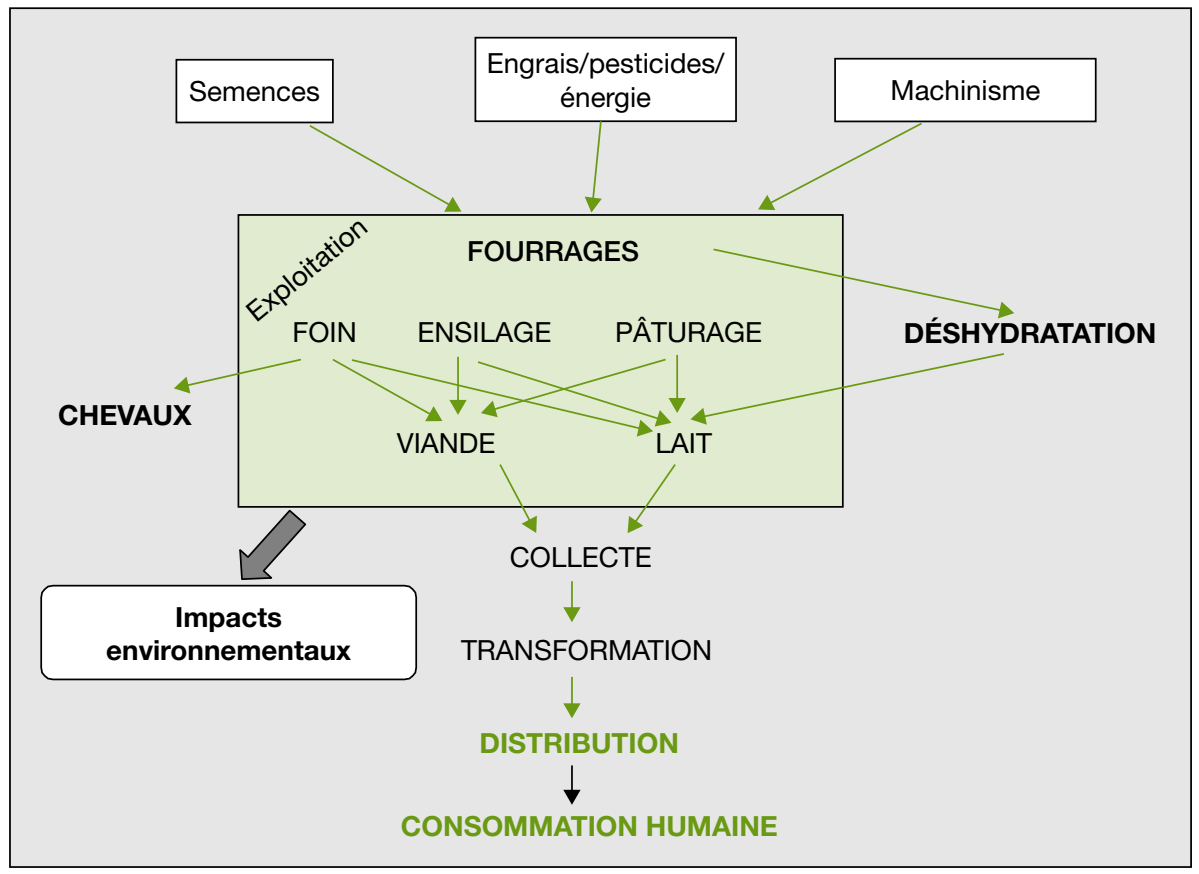

Figure 1. Les prairies et cultures fourragères au cœur d'une filière complexe.

Figure 1. Grasslands and forage crops are part of a complex supply chain. peut considérer que cet ensemble est également une fonction de production.

Enfin, le troisième ensemble de fonctions est relatif aux impacts et bénéfices environnementaux. Cela est très important en raison de la part de la surface agricole utile (SAU) occupée par les prairies et cultures fourragères.

Considérant la structure de la filière et les fonctions assignées à la prairie, quatre caractéristiques contribuent à rendre cette filière de production unique parmi les surfaces cultivées et les productions agricoles françaises.

Tout d'abord, en considérant cette filière en termes de flux de matières et de biens de consommation, on note que le sens de la régulation s'est inversé au cours des dernières décennies. En effet, au cours des Trente Glorieuses, la capacité à produire des biens destinés à l'alimentation humaine était le facteur limitant et l'accent était mis sur l'augmentation de la production. Cela explique notamment le rôle des industries d'approvisionnement et du secteur semencier durant cette période. Depuis 20 ans et l'atteinte de l'autosuffisance alimentaire, la régulation s'est inversée et la capacité à consommer ou à exporter détermine la capacité à produire.

Le deuxième point majeur est la particularité des prairies et cultures fourragères d'être autoconsommées au sein de l'exploitation, à l'exception des surfaces destinées à la déshydratation ou aux ventes de foin. En conséquence, la biomasse produite n'a pas de valeur marchande intrinsèque, sa valeur étant déterminée à l'aune de la production animale. La situation est différente en Amérique du Nord où il existe un marché très important de fourrages lié aux échanges entre exploitations.

La troisième considération est que le fourrage issu des prairies et cultures fourragères est substituable. Cela peut se produire entre les différentes catégories de ce vaste ensemble. Le fourrage peut aussi être pour partie remplacé par des aliments 
concentrés (céréales, oléoprotéagineux) et de la paille.

Enfin, cette filière combine de façon intime des enjeux marchands, de production, et des enjeux non marchands, de préservation de l'environnement.

Cette réflexion sur la multifonctionnalité des prairies sera déclinée en deux articles. Ce premier article sera consacré aux fonctions de production. Nous y présenterons, pour les dernières décennies et avec un éclairage sur une période plus longue, des éléments sur les surfaces concernées et les productions animales herbivores. Puis, nous montrerons comment les prairies assurent la production de matière première fourragère concourant à la performance économique des exploitations agricoles et contribuent à la qualité des produits.

Un second texte sera consacré à l'analyse de la contribution à la préservation de l'environnement et aux conditions nécessaires à la combinaison des fonctions productives et environnementales.

\section{Prairies et productions herbivores en France}

\section{Cultures fourragères et prairies}

Évolution des surfaces

en prairies et cultures fourragères

au cours des dernières décennies

Les prairies et cultures fourragères occupent plus de 14,7 millions d'hectares et représentent $45 \%$ de la surface agricole utile (SAU) française. Les surfaces toujours en herbe (STH) (prairies permanentes et prairies semées de plus de 5 ans) constituent $66 \%$ de l'ensemble. Les prairies temporaires (surfaces semées âgées de 1 à 5 ans) et les fourrages annuels couvrent respectivement 2,3 millions d'hectares et 1,7 million d'hectares.

La répartition des surfaces sur le territoire national montre une prédominance des surfaces semées (fourrages annuels, prairies temporaires) au nord-ouest d'une ligne Bordeaux-Nancy et des surfaces toujours en herbe au sud-est de cette ligne. Dans la moitié nord-ouest, où est la majorité des ruminants laitiers, les STH vont avoir un rôle environnemental crucial, alors que dans la moitié sud-est, les surfaces semées assurent souvent la sécurité des systèmes fourragers.
Les surfaces en prairies permanentes ont perdu près de 3 millions d'hectares au cours des trois dernières décennies (figure 2), pour moitié au bénéfice des landes et forêts. Cela a un impact majeur sur la structure des paysages agricoles. La profonde réforme de la Politique agricole commune (PAC) de 1992 n'a pas eu l'effet que l'on aurait pu attendre. En effet, malgré un soutien à la surface favorable au maïs ensilage, les surfaces de cette culture ont peu augmenté tout en se déplacant légèrement. La raison réside dans l'existence d'autres stabilisateurs puissants, notamment: i) la diminution du nombre de vaches laitières, premières consommatrices de ce fourrage conservé ; ii) un système fourrager avec une présence déjà massive de maîs ensilage avant la réforme de la PAC ; et iii) la possibilité d'incorporer des céréales à bas prix dans les rations des animaux à haute performance. Ce dernier point, très dépendant du prix de marché mondial des céréales, se trouve à ce jour profondément modifié.

La décroissance régulière des prairies artificielles, cultures pures de légumineuses pérennes, durant les dernières décennies est la fin d'un processus complexe au long du siècle dernier avec quatre grandes périodes successives (figure 3):

- une période de grande stabilité avant la seconde guerre mondiale, les légumineuses étant au cour des systèmes de production, fournissant d'une part une biomasse fourragère et étant d'autre part une source de fertilisation azotée des systèmes grâce à la fixation symbiotique. En 1930, au 1,3 million d'hectares de luzerne, il convient d'ajouter 500000 hectares de trèfle violet et 300000 hectares de sainfoin qui jouent les mêmes fonctions dans des conditions pédoclimatiques différentes. Cette fonction de source azotée dans les rotations disparaît avec l'utilisation croissante des engrais azotés de synthèse, dont la généralisation est forte à l'issue de la seconde guerre mondiale :

- une période de forte croissance pour répondre aux besoins en protéines des élevages ruminants en fort développement ; - une brutale décroissance de ces cultures, récoltée en foin et donc très gourmande en main-d'œuvre. Cela correspond à une période de forts mouvements des populations rurales vers l'industrie, ainsi qu'au développement de l'industrie de déshydratation de la luzerne qui permet de réduire la demande en maind'œuvre ;

- une lente décroissance qui exprime la substitution des rations à base de luzerne par des concentrés et notamment le tourteau de soja.

\section{Evolution des surfaces en prairies et cultures fourragères au cours des derniers siècles}

Pour analyser l'évolution des surfaces en prairies sur des pas de temps plus longs, on dispose de données statistiques nationales depuis le début du $\mathrm{XIX}^{\mathrm{e}}$ siècle

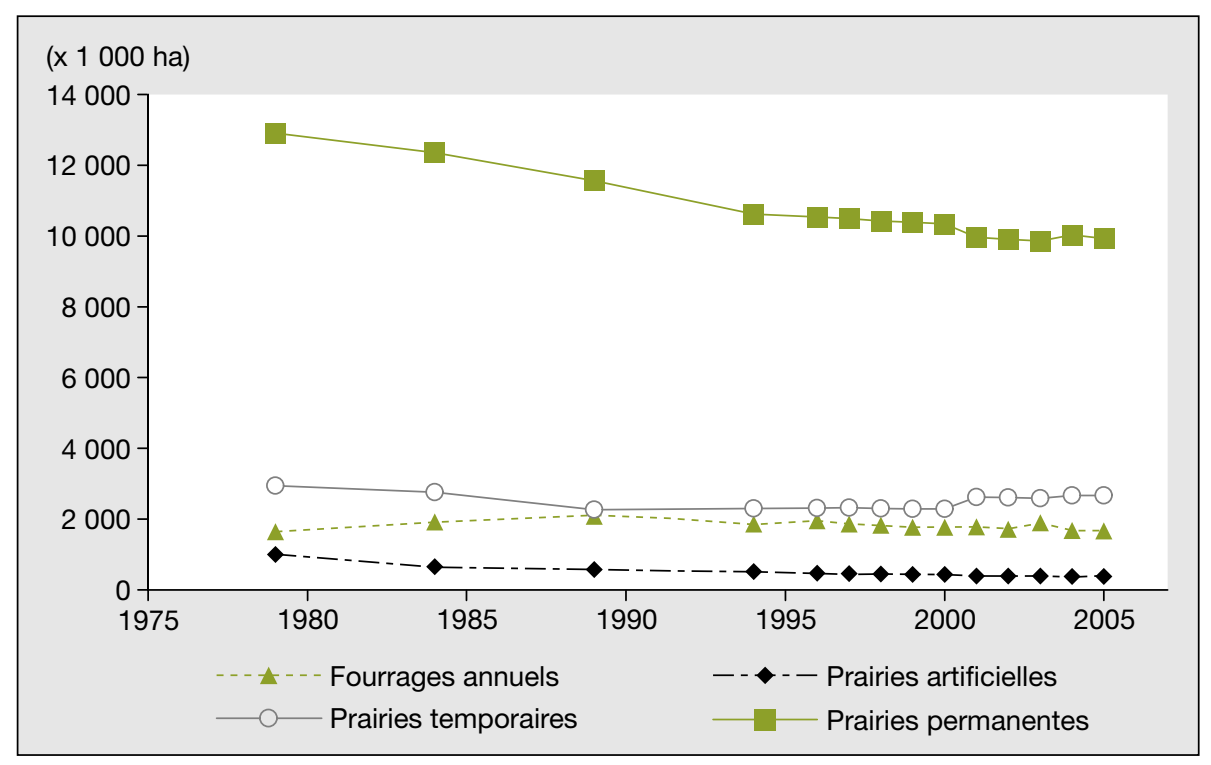

Figure 2. Évolution des surfaces des différents types de prairies et cultures fourragères en France depuis 1979.

Figure 2. Changes in acreage of the various types of grasslands and forage crops in France since 1979. 


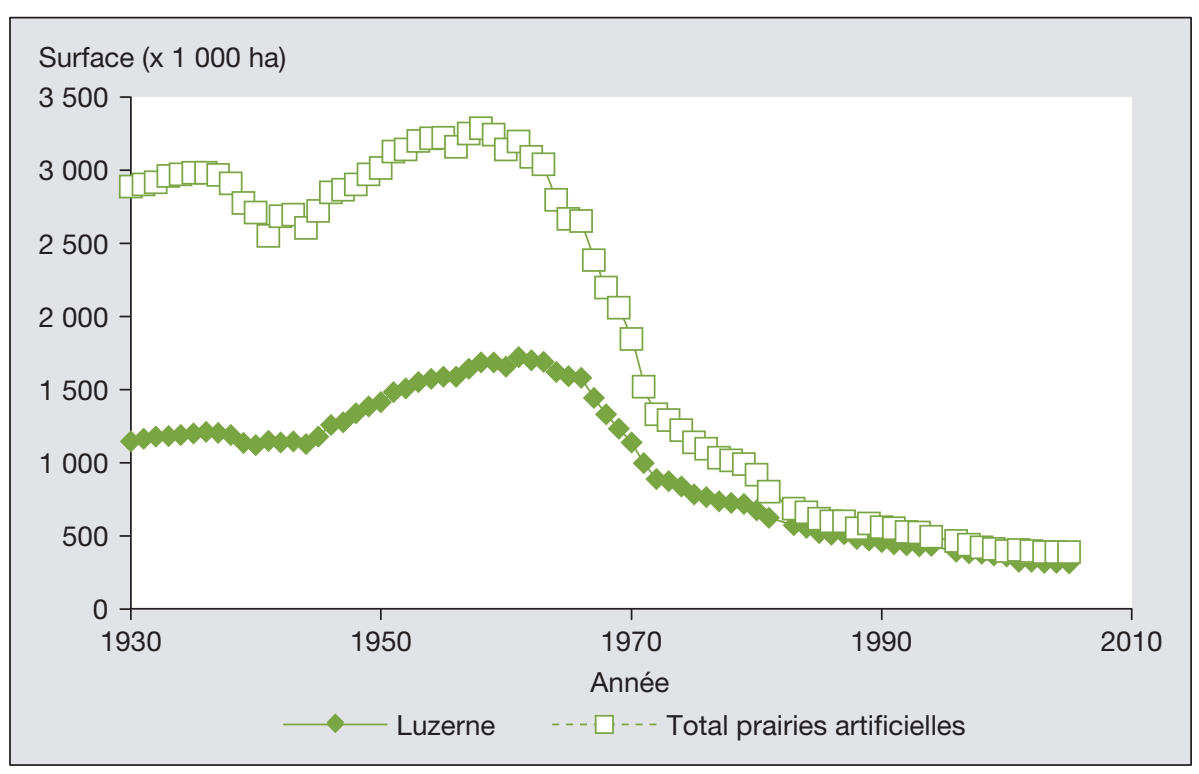

Figure 3. Évolution des surfaces de luzerne et en prairies artificielles en France depuis 1930.

Figure 3. Changes in acreage of alfalfa and forage legumes in France since 1930.

(figure 4). Cependant, tout au long du XIX ${ }^{\mathrm{e}}$ siècle, les surfaces en landes ne sont pas comptabilisées parmi les prairies naturelles alors qu'elles servent épisodiquement à l'alimentation des troupeaux. Le début du XIX ${ }^{\mathrm{e}}$ siècle marque une rupture agronomique puisque les bénéfices de l'utilisation des prairies artificielles en assolement avec des céréales commencent à être largement connus et utilisés.

Gilbert (1787) avait montré, dans une communication à l'Académie royale d'agriculture, comment différentes légumineuses fourragères étaient utilisées dans le grand Bassin parisien en fonction des types de sols et des expositions. Il vulgarisait leurs effets bénéfiques sur la productivité agricole.

Les prairies temporaires connaissent un développement à partir du milieu du

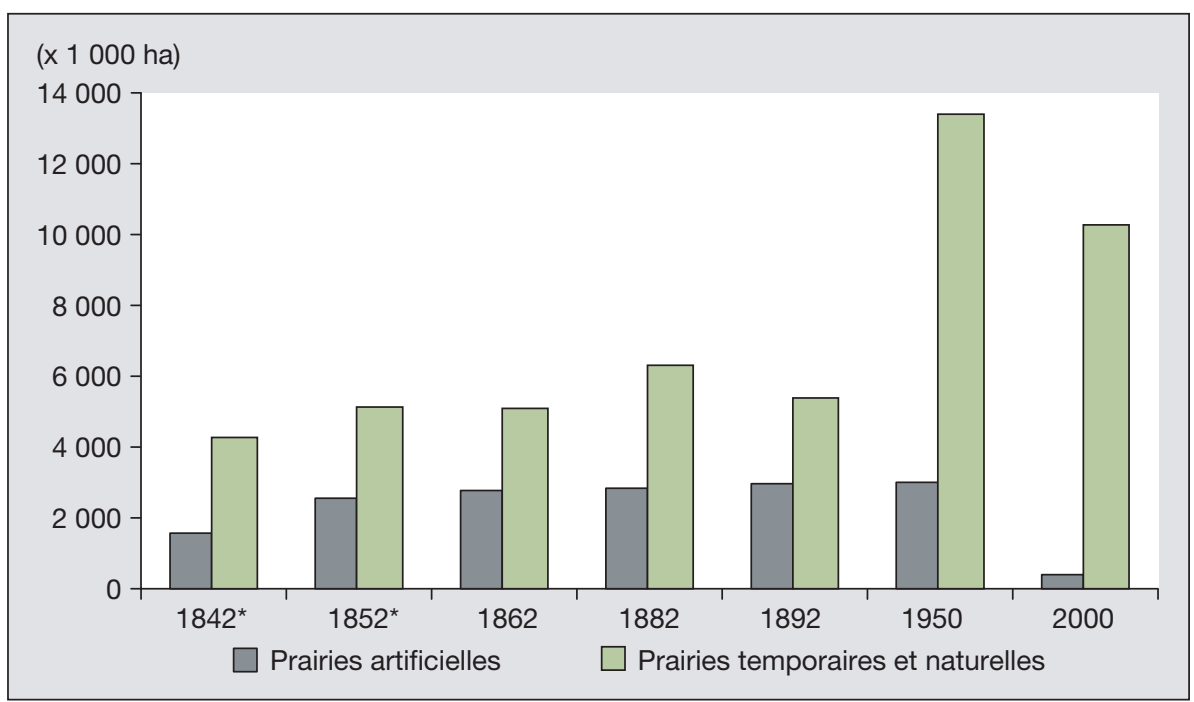

Figure 4. Évolution des surfaces en prairies artificielles et en prairies temporaires et naturelles depuis le début du XIX $X^{\mathrm{e}}$ siècle.

Figure 4. Changes in acreage of perennial forage legumes and cultivated perennial grasslands since the early 19th century.

Avant 1900, les surfaces en landes pâturées ne sont pas prises en compte.
$\mathrm{XIX}^{\mathrm{e}}$ siècle dès que l'on met en évidence leur capacité à produire plus de biomasse que les prairies permanentes. Ce progrès provient de trois sources.

Tout d'abord d'une gestion appropriée de l'eau. En effet, les prairies permanentes sont souvent réservées aux zones humides où, de plus, les plantes ayant un enracinement superficiel ont donc une mauvaise résistance à la sécheresse estivale. Comme le fait remarquer Querret (1845) dans un ouvrage sur l'amélioration des prairies en Basse Bretagne, le premier déterminant dans l'amélioration des prairies est le creusement de canaux pour gérer l'eau.

La deuxième étape est l'utilisation d'espèces appropriées et de semences de qualité. Les ouvrages d'agronomie des XVIII et $\mathrm{XIX}^{\mathrm{e}}$ siècles montrent des évolutions dans les espèces utilisées, certaines espèces très utilisées aujourd'hui, comme la fétuque élevée (Boitel, 1887), étant alors rejetées faute de populations adaptées. Les semences sont souvent de médiocre qualité, issues des greniers à foin ou battues à partir des foins (fleur de foin). Les semences récoltées à dessein sont à des prix très élevés. On peut ainsi, d'après les éléments fournis par Querret (1845), calculer que le salaire d'une journée de travail permet à un homme d'acquérir 2,5 kilos de semences pour prairies.

Enfin, la troisième étape est la fertilisation par l'utilisation des déjections animales. Les fumiers sont en général réservés aux terres emblavées en cultures annuelles et la fertilité des sols est souvent limitée. L'utilisation de légumineuses permet de limiter la contrainte azotée.

À ces surfaces, il faut ajouter un vaste ensemble de surfaces peu productives ayant pour dénominations landes, pacages, pâtures, bruyères. Selon les données statistiques de 1882, le total de ces surfaces atteint 6 millions d'hectares. Leur productivité et leurs utilisations sont mal documentées. Toutefois, leur prix de vente fournit une précieuse indication de l'importance de ces surfaces pour la vie des exploitations. Ainsi, selon l'étude de Delhoume (2004) portant sur une commune du Limousin en 1742, le revenu des prés de fauche est supérieur au revenu des vignes et varie de 13,2 à 20,60 livres/ha pour une moyenne de 16,9, alors que le revenu des pâturages varie de 4 à 8,50 livres/ha pour une moyenne de 6,27. Cela souligne à la fois la différence de productivité des deux types de surfaces et le caractère crucial 
des stocks issus des prés de fauche pour la survie des exploitations.

\section{Évolution des pratiques de récolte} et de fertilisation

Les prairies et cultures fourragères sont aujourd'hui exploitées en pâturage, foin ou ensilage. Au cours des dernières décennies, les modifications ont été en premier lieu le développement des ensilages chez le mais et chez les graminées fourragères où la pratique du préfanage et l'addition d'acides permettent d'améliorer les réussites et de réduire les taux de pertes. Par ailleurs, le développement des balles rondes depuis 1978 et de séchage en grange réduit la pénibilité du travail, simplifie son organisation et améliore la qualité des fourrages conservés.

Les niveaux de fertilisation minérale, et notamment azotée, ont été profondément modifiés au cours de ces décennies. Partant d'une fertilisation minérale très faible au début du $\mathrm{xx}^{\mathrm{e}}$ siècle, les associations étant la norme, la révolution fourragère a démontré l'importante augmentation des productions de biomasse des cultures de graminées sous des fertilisations minérales azotées élevées. Cela a conduit à des recommandations de fertilisation élevée atteignant $500 \mathrm{~N}$ et sur des cultures pures de graminées. Ainsi, Hnatyszyn rapporte en 1975 des études conduites en Pays d'Auge, sur fétuque élevée, de 1968 à 1971, avec des fertilisations azotées moyennes annuelles comprises entre 170 et 860 unités par hectare, certaines variétés présentant une production maximale au niveau le plus élevé (Hnatyszyn, 1975). En raison du coût et des préoccupations environnementales, les fertilisations sont aujourd'hui beaucoup plus limitées dépassant rarement $150 \mathrm{~N}$ sur prairies de graminées avec une place croissante aux prairies multispécifiques associant graminées et légumineuses.

En conséquence de ces évolutions de pratiques, et de la sélection variétale, les rendements en biomasse ont augmenté au cours des dernières décennies. Ce point a été bien documenté sur le mais ensilage. Pour les cultures fourragères pérennes, les fortes fertilisations minérales ont conduit à de grandes augmentations de production de biomasse récoltable en ensilage. Les évolutions récentes des pratiques ont amélioré la production et la facilité de conduite pour des utilisations au pâturage. La sélection variétale a contribué à améliorer la valeur agronomique des espèces fourragères pérennes. Chez l'ensemble des espèces, un progrès très important a été accompli sur la résis- tance aux maladies et aux parasites. C'est en particulier le cas de la résistance aux rouilles chez les graminées fourragères et chez la luzerne de la résistance au Verticilium, à l'anthracnose et au nématode des tiges. Pour les espèces principalement dédiées à la constitution de stocks, l'amélioration notable de la résistance à la verse contribue à faciliter les récoltes. La productivité a surtout été améliorée chez le dactyle avec la sélection de variétés à démarrage en végétation plus précoce et à épiaison tardive. Ces variétés plus souples d'exploitation viennent corriger ce qui était le défaut majeur des anciennes variétés et populations.

\section{Productions animales herbivores}

\section{Évolution des effectifs animaux} au cours des dernières décennies

Les 30 dernières années sont marquées par trois éléments importants. Dans le cheptel des petits ruminants, $10 \%$ des unités de gros bétail (UGB), il y a, d'une part, une très forte stabilité des effectifs de chèvres laitières concentrés dans deux régions principales de production, pour une collecte de lait qui a été multipliée par 3 durant cette période et, d'autre part, une forte décroissance du nombre d'ovins, par diminution des ovins viande (figure 5).
Le cheptel des vaches laitières (VL) a décru fortement en raison d'abord de l'application des quotas laitiers (1984), puis de l'augmentation de la production laitière moyenne $(7500 \mathrm{~kg} / \mathrm{VL} / \mathrm{an}$ au contrôle laitier en 2005 contre 4700 en 1980). A contrario, l'effectif des vaches allaitantes a augmenté pour atteindre celui du troupeau laitier, soit 4 millions de têtes. Cette balance est liée au fait que la consommation de viande bovine, bien que diminuant, s'est maintenue à un haut niveau en France, ce qui a conduit à un déplacement des régions de production herbivore. Seule, parmi les régions laitières, la région Pays de Loire a maintenu ses effectifs bovins.

Les équins représentent $5 \%$ des UGB en France, en 2005. Leur nombre a fortement augmenté au cours des 25 dernières années pour atteindre 418000 têtes, en majorité des animaux destinés au loisir ou au sport. Les chevaux se différencient des autres herbivores car la prairie est souvent pour eux un espace d'exercice où l'on ne cherchera pas à augmenter la quantité de fourrages produits, mais où l'attente en termes de pérennité du couvert est forte. Les propriétaires de ces animaux ont parfois une connaissance du végétal plus faible, même s'ils se professionnalisent rapidement. Enfin, les équins, par leur mode d'herbivorie (tonte rase et forte hétérogénéité de la prairie),

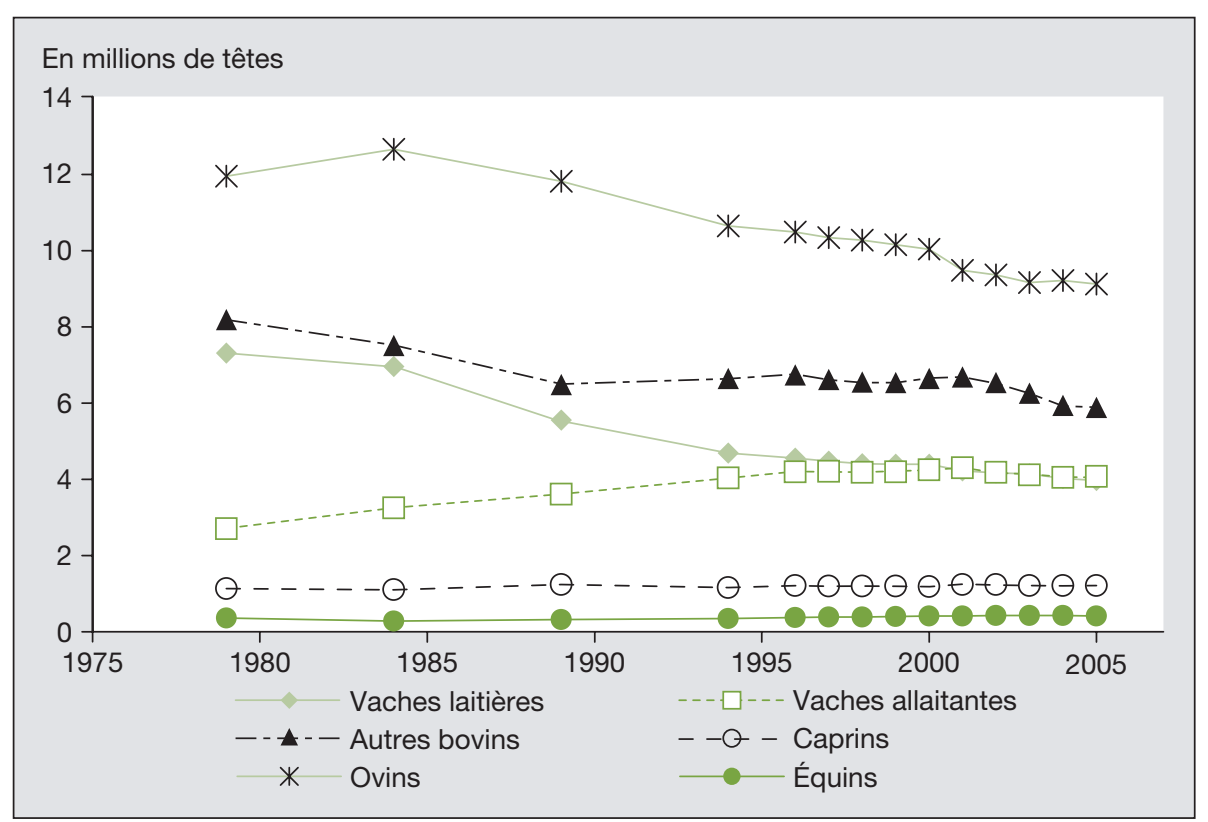

Figure 5. Évolution des cheptels herbivores en France depuis 1979.

Figure 5. Changes in herbivore herds in France since 1979. 
exercent sur le couvert végétal une pression intense et différente de l'effet des bovins. Cela conduira à une évolution particulière de la flore (Loucougaray et al., 2004) et à la création d'hétérogénéité spatiale (Adler et al., 2001).

Les implications de ces changements sur les prairies sont fortes. Pour les vaches laitières, la composition des rations a évolué avec l'augmentation des performances animales, par un accroissement de la part des fourrages conservés et des concentrés et une réduction de la part du pâturage. La ration fourragère des troupeaux allaitants comprend une part plus importante de prairies pérennes pâturées et en particulier de prairies permanentes. La diminution de la part des prairies dans la ration des vaches laitières est aussi à rechercher dans les préoccupations des éleveurs en termes de charge de travail et de recherche de sécurité quant à la ressource fourragère disponible. Cela conduit à une utilisation plus importante de fourrages conservés.

Les conséquences des évolutions des effectifs animaux permettent de souligner l'importance cruciale pour l'ensemble de la filière du maintien de la consommation des produits laitiers et carnés. À ce titre, la comparaison avec l'Allemagne est intéressante. En effet, dans ce pays, la diminution du nombre de vaches laitières a été simultanée à une forte décroissance de la consommation de viande rouge. Cela a conduit à une absence de développement d'un cheptel allaitant (Huyghe et al., 2006).

\section{Évolution des effectifs herbivores au cours des derniers siècles}

Comme pour les prairies, on dispose de données statistiques couvrant les deux derniers siècles. Une synthèse de quelques données significatives est proposée à la figure 6.

Ce pas de temps long met en évidence certains grands phénomènes :

- un effectif caprin constant ;

- une augmentation constante du nombre de bovins, avec une accélération particulièrement marquée après la seconde guerre mondiale. Au long du XIX ${ }^{\mathrm{e}}$ siècle, ces bovins contribuaient surtout à fournir une force de traction dans bon nombre de régions ;

- un effectif équin (chevaux, ânes et races mulassières) constant jusqu'en 1950, suivi d'un effondrement brutal. L'arrivée de la force de traction mécanique a fait disparaître ce troupeau des zones où il était implanté ;

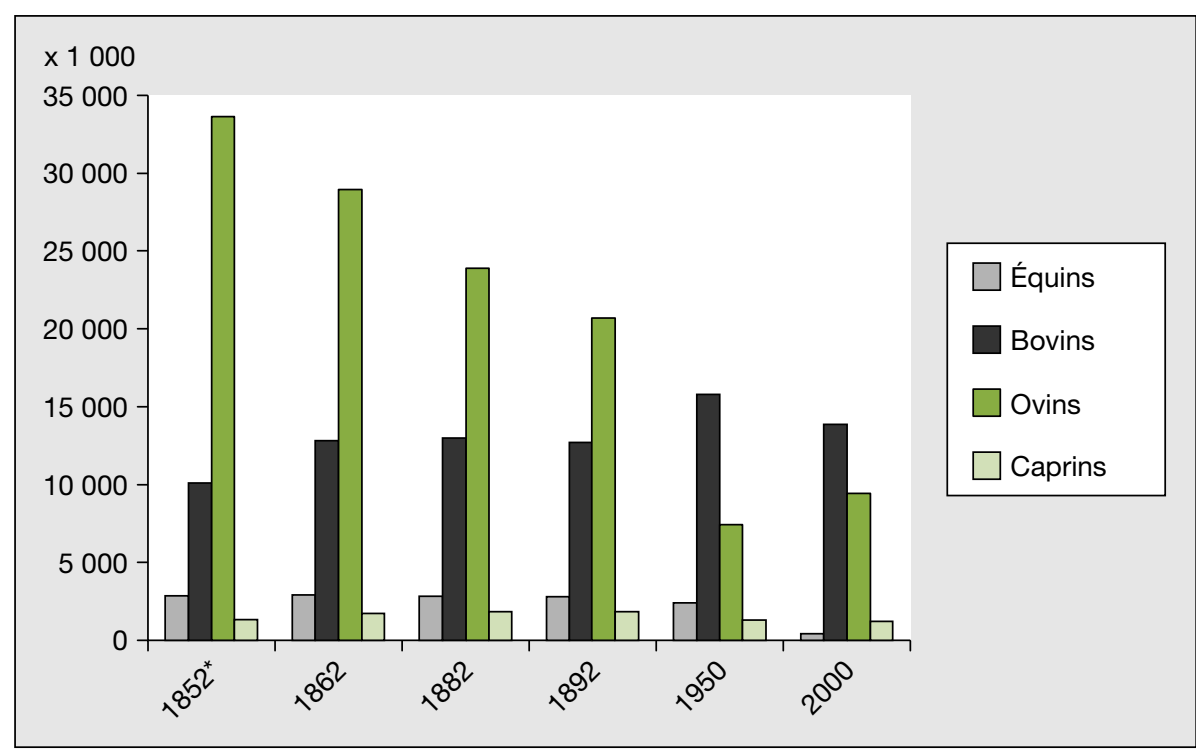

Figure 6. Évolution des effectifs des différents troupeaux d'herbivores en France au cours des deux derniers siècles.

Figure 6. Changes in numbers of herbivores in France during the last two centuries.

*En 1852, la Savoie, non française, n'est pas prise en compte.

- un effectif ovin en diminution régulière au long de ces deux siècles. Ce troupeau a connu son apogée sous l'effet du développement de l'industrie lainière, notamment sous l'impulsion de Colbert.

Au regard de ces données, on peut constater qu'au long des deux derniers siècles, les prairies et cultures fourragères ont eu pour fonction première la fourniture de matières premières alimentaires pour les herbivores domestiques, ceux-ci étant à la fois sources de produits animaux destinés à l'alimentation humaine et force de traction. Au-delà de cette fonction de production, elles étaient aussi une source de fertilité pour l'ensemble des rotations où elles étaient insérées. Nous avons souligné dans les lignes précédentes la fonction de source de fertilité azotée pour les légumineuses, et plus généralement via l'utilisation des déjections animales. Cette utilisation et donc l'importance du couplage entre élevage et cultures annuelles étaient déjà soulignées par O. de Serres en 1600 dans son célèbre ouvrage $L e$ Théâtre d'Agriculture et Mesnage des Champs.

\section{Évolution des chargements animaux}

Le chargement animal moyen en France est aujourd'hui de 1,2 UGB/ha de surface fourragère principale (SFP). Cette moyenne nationale cache de grandes disparités entre systèmes de production et entre régions. Ainsi, sur la base des réseaux de l'Institut de l'élevage, les chargements en production laitière bovine varient de 1,7 en exploitations associant lait et cultures à 1,0 pour les exploitations spécialisées lait en zones de piémont et montagne. En bovins allaitants, les chargements varient de 1,52 en systèmes naisseurs-engraisseurs de jeunes bovins à 1,1 en naisseurs-engraisseurs de veaux.

Les disparités entre régions sont également importantes, depuis 1,54 en zone herbagère du Nord-Ouest à 0,61 en zone pastorale de la bordure méditerranéenne.

$\mathrm{Au}$ cours des dernières décennies, les chargements ont peu varié, puisque le chargement calculé pour 1979 donne une valeur de 1,16. La comparaison avec le siècle précédent est plus difficile compte tenu du statut mal défini des landes, pacages, pâtures et bruyères. En faisant l'hypothèse que la moitié de ces surfaces peuvent être introduites dans la SFP, on obtient alors un chargement calculé de 1,64 pour l'année 1882. Ce chargement calculé plus élevé ne signifie pas pour autant que la productivité des prairies était plus élevée. Il peut être lié au fait qu'une part significative des UGB herbivores est nourrie à partir d'autres surfaces (ovins en régions céréalières, chevaux) et que la productivité animale individuelle (production de lait par exemple) étant plus faible, les UGB ne sont pas totalement comparables. Le format moyen des 
animaux était sans doute plus petit, comme le suggèrent les travaux de Moriceau (2005) pour la fin du XVIII siècle.

\section{Fonctions}

\section{de production}

\section{assignées aux prairies et cultures fourragères}

Pour identifier les fonctions assignées aux prairies, ou susceptibles de l'être, il faut analyser les déterminants de leur utilisation aux yeux des différents acteurs de la filière ou aux yeux de la société, tout à la fois consommatrice de biens alimentaires et de services environnementaux. Cette approche, basée sur les acteurs, permet de définir trois fonctions essentielles, à savoir la contribution à la performance socio-économique des exploitations d'élevage, la contribution à la qualité des produits animaux et la contribution à la préservation de l'environnement, cette dernière fonction étant traitée dans un second article.

\section{Performance \\ socio-économique des exploitations d'élevage}

Cette fonction s'insère dans l'objectif des éleveurs de recherche d'un équilibre satisfaisant entre le revenu, issu des produits animaux vendus, et le travail. Les pratiques et modes d'exploitation des prairies et cultures fourragères peuvent contribuer à mieux assurer cette fonction par la recherche d'une augmentation de la production fourragère par unité de surface (démarche au centre de la révolution fourragère) et d'une diminution des coûts de production. L'exploitation par le pâturage et l'amélioration de la qualité (teneur en protéines, digestibilité, ingestibilité) concourent à obtenir les coûts de production les plus bas. Cette fonction historique des prairies et cultures fourragères a été déterminante dans l'élaboration des modes de conduite et d'exploitation de ces surfaces, mais aussi dans la définition des principales politiques publiques qui ont eu cours jusqu'à la réforme de la PAC de 1992, ou encore dans les principales thématiques de recherche finalisée ou appliquée au cours des dernières décennies.
La combinaison des cultures fourragères et des différents types de prairies, et l'utilisation de différents modes de récolte permettent d'élaborer un système fourrager couvrant les besoins des troupeaux au coût le plus bas par unité d'énergie alimentaire (unité fourragère) ou de protéines digestibles. Cependant, le coût de production ou le revenu n'est pas la seule préoccupation des éleveurs. En effet, la charge de travail et l'incertitude liée au processus de production, en particulier la sensibilité aux aléas climatiques, doivent également être prises en considération.

L'éleveur doit en effet gérer un ensemble diversifié de surfaces, dans un environnement pédoclimatique donné mais variable, avec différents modes de production pour répondre à un compromis d'objectifs et de contraintes. Aussi, dans un même milieu, des systèmes fourragers très différents pourront alors être mis en place pour répondre aux priorités différentes d'éleveurs voisins.

On peut ici illustrer comment différentes surfaces fourragères et différents modes de production répondent à ces objectifs.

Le pâturage est un mode de valorisation de la prairie économe (Le Gall et al., 2001) car il limite les charges de structure et les investissements et est peu exigeant en main-d'œuvre. La combinaison d'un pâturage tournant avec de nombreuses parcelles de taille limitée, l'utilisation d'outils d'aide au pilotage et la constitution de stocks sur pied permettent d'offrir aux animaux un fourrage de qualité sur une grande partie de l'année. Le pâturage est en revanche sensible aux aléas climatiques, en particulier le stress hydrique, obligeant à un dimensionnement des surfaces permettant de couvrir les besoins dans la plupart des situations. Pour les années les plus extrêmes, d'autres solutions doivent être envisagées, comme par exemple les achats de fourrages et de paille, parfois avec l'aide de l'Etat et des organisations professionnelles comme lors des grandes sécheresses de 1976 et 2003. Le système reposant sur le pâturage est donc d'autant plus approprié que les contraintes climatiques sont faibles et les variations interannuelles limitées. L'utilisation de prairies semées multispécifiques avec des espèces et des variétés judicieusement choisies pour obtenir la diversité spécifique et fonctionnelle adaptée au milieu et aux pratiques permet d'augmenter la pérennité de la valeur agronomique de ces prairies, limitant ainsi les besoins de renouvellement. Elle permet aussi de combiner dans le sys- tème fourrager des couverts exploitables tôt au printemps et d'autres avec une meilleure croissance estivale. Cependant, cela conduit à des plannings de pâturage complexes, exigeant un savoir-faire important de l'éleveur. De plus, la sécurité d'un système fourrager centré sur le pâturage exige la constitution de stocks. En conséquence, l'ensemble génère des incertitudes. L'éleveur, pour se conforter, doit alors compter sur son expérience acquise au fil des années ou sur des démarches de groupes (voir les démarches du Centre d'études pour le développement d'une agriculture plus autonome (Cedapa), des Centres d'initiatives pour valoriser l'agriculture et le milieu rural (Civam) ou de groupes d'éleveurs (Opti Pâture, 2007).

À l'opposé, des systèmes reposant sur les stocks sont beaucoup plus sécurisés, surtout si les stocks peuvent être reportés d'une saison ou d'une année à l'autre (foins). Une alimentation à base d'ensilage de maïs complémenté par du tourteau de soja comporte peu d'incertitude quant à la quantité de fourrage disponible ou à sa qualité alimentaire. C'est en particulier le cas si, en zones à risques de sécheresse estivale, l'éleveur dispose d'une irrigation d'appoint. Cette sécurité s'affaiblit en régions à contraintes hydriques estivales marquées si le maïs ne peut être irrigué. Toutefois, ces systèmes sont plus onéreux.

Cette même analyse peut s'appliquer aux modes de conservation des fourrages. Pour la constitution de stocks à partir de prairies temporaires ou permanentes, l'éleveur peut utiliser le foin (stock reportable sur de très longues périodes) ou l'ensilage avec des variantes pour chacun de ces modes de récolte. La production de foin, aujourd'hui fortement mécanisée, est peu exigeante en main-d'œuvre et permet beaucoup d'autonomie. Elle souffre en revanche d'une très grande sensibilité aux conditions climatiques (pluviométrie). L'évolution vers un système de séchage en grange permet de limiter, voire de supprimer, cette sensibilité, avec les productions de foin de très grande qualité, mais a un coût élevé, en particulier en investissement initial.

Cette fonction de production de ressources alimentaires et ainsi de contribution à la performance économique des exploitations pourrait être perturbée au cours des prochaines années par l'émergence dans la sphère agricole de la production de biomasse destinée à l'industrie (biocarburant, biomatériaux) et cela de 
différentes façons. Tout d'abord, ces nouvelles productions vont engendrer une compétition sur les surfaces disponibles avec une augmentation possible du prix du foncier ou une diminution des surfaces utilisables en production fourragère et la nécessité d'en augmenter la productivité. Une partie des prairies et cultures fourragères pourrait être utilisée à des productions de biomasse destinée à l'industrie. En effet, Tilman et al. (2006) ont démontré la compétitivité de ces cultures en termes de production ou d'écobilan par rapport à des cultures productrices d'huile ou d'amidon. La disponibilité de coproduits issus de cette industrie et utilisables en alimentation du bétail peut modifier les attentes en termes de coût et de qualité des fourrages. Enfin, la demande en matières premières destinées à des utilisations industrielles non alimentaires, en générant une augmentation du prix des grains, pourrait par ricochet augmenter la valeur marchande indirecte de prairies et cultures fourragères productives.

Toute réflexion sur la performance économique des exploitations doit également prendre en compte la dimension de la charge et de la pénibilité du travail, mais aussi des incertitudes liées au travail et aux marchés. L'organisation du travail et les choix techniques dont les choix sur les prairies et cultures fourragères dépendent de la composition de la maind'œuvre à l'échelle de l'exploitation, des choix personnels des éleveurs et des autres charges à assurer (Dedieu et al., 2006). La composition de la maind'œuvre a fortement changé en élevage au cours des deux dernières décennies, avec une part très importante des jeunes conjointes d'exploitants qui exercent une activité professionnelle hors de l'exploitation. Cela affecte la force de travail disponible en engendrant éventuellement de l'emploi salarié, mais conduit aussi à une autre relation entre l'exploitation et son environnement. La recherche de la simplification est une réponse possible à la diminution de la main-d'œuvre ou à la recherche de flexibilité (Cournut et Dedieu, 2005). Les réponses dans les exploitations peuvent alors être très diverses car les décisions de gestion des éleveurs sont affectées par des indicateurs différents relatifs à la performance des animaux et du troupeau, à la maximisation du potentiel animal ou à l'utilisation optimale de la ressource fourragère. Cela traduit surtout la diversité des significations données par les éleveurs au terme de simplification. Les métiers de production animale génèrent une incertitude importante, d'une part en raison des variations de production fourragère entre années et au long de l'année, et d'autre part à la variation des cours de production animale, variations plus importantes en production de viande que de lait (Lemery et al., 2005). La particularité des systèmes herbivores tient à leur temps d'adaptation long, notamment quand il s'agit de répondre aux marchés. Les politiques publiques peuvent venir sécuriser les cours à moyen et long termes, les quotas laitiers ont été un outil efficace pour cela. Mais, pour la ressource fourragère, le choix technique est crucial. Les systèmes reposant sur les rations sèches sont les plus sécurisés. Pour les systèmes reposant sur des prairies et cultures fourragères, la part des stocks et la capacité à piloter la ressource et à prédire le nombre de jours d'avance permettent de limiter les risques et d'anticiper les périodes difficiles.

\section{Qualité des produits animaux}

Cet enjeu important détermine pour le producteur et le transformateur le prix de vente et l'accession au marché. Il conditionne aussi la taille du marché ellemême. En effet, en France, la consommation de produits laitiers dépasse $400 \mathrm{~kg}$ équivalents lait par an et par habitant. Supérieure aux besoins alimentaires stricts, elle s'explique par les traditions culturelles et alimentaires et par le plaisir, indissociable de la réponse des produits à l'attente des consommateurs.

Le lien avec la prairie peut paraître ténu. Pourtant, il existe une relation entre alimentation fourragère et qualité des produits animaux.

Les synthèses faites par Coulon et Priolo (2002) et Coulon (2006) décrivent de façon exhaustive la relation entre composition de la ration fourragère et composition des produits animaux.

En production laitière, les études en stations ou en exploitations montrent que la quantité et la nature de l'herbe offerte aux animaux sont des leviers pour moduler la composition biochimique en macroconstituants du lait, et répondre aux demandes du marché, notamment pour une diminution de la teneur en matières grasses. Les qualités sensorielles du lait et des fromages sont également affectées. Par rapport à l'herbe offerte en foin, en ensilage ou pâturée, le maïs conduit à des fromages et des beurres plus blancs (en relation à la plus faible teneur en carotènes) et plus fermes. La teneur en carotènes diminue chez les fourrages séchés avec une longue exposition à la lumière. Chez la chèvre, Gaborit et al. (2002) ont montré que le foin de luzerne, comparé au maïs ensilage, permettait la production de fromages avec une flaveur plus intense.

La conservation en ensilage peut conduire à des défauts spécifiques en productions fromagères, notamment en pâte pressée cuite où la présence de spores butyriques dans l'ensilage puis dans le lait génèrent des gonflements tardifs, de mauvais goûts et des odeurs peu appréciées. Pour des ensilages bien conservés, les différences gustatives sont faibles mais varient selon les types de fromages.

En revanche, les différences sont fortes entre les fromages issus des laits d'hiver avec ration à base de foin ou d'ensilage et des laits d'été à base d'herbe pâturée. En Saint-Nectaire ou en Cantal, les fromages de laits d'été sont plus jaunes, avec une texture moins ferme, un goût plus intense et une odeur moins piquante et moins aigre que ceux issus des laits d'hiver. Cet effet positif de l'herbe pâturée semble pouvoir être obtenu avec des apports limités d'herbe en complément d'une ration sèche.

La composition botanique de la prairie pâturée a une influence sur la qualité des laits et la qualité sensorielle des produits laitiers, sans que l'hypothèse de l'effet de la richesse en terpènes de certaines espèces botaniques ait pu être confirmée.

La composition de la ration fourragère a également un effet sur les caractéristiques nutritionnelles des laits et notamment sur les teneurs en vitamines A et $\mathrm{E}$, en carotènes et en composés phénoliques. Le pâturage, en particulier d'herbe jeune, augmente la proportion des acides gras polyinsaturés et la teneur en acide ruménique (CLA) avec des effets positifs sur la teneur en vitamines A et E et en caroténoïdes et sur la santé humaine. Cet effet diminue lors d'une conservation sous forme d'ensilage et plus encore sous forme de foin. Cet effet positif du pâturage est plus marqué dans des prairies d'alpage, peut-être en raison de la composition botanique de ces prairies.

Sur la viande, issue d'un processus d'accumulation sur de longues périodes, les effets sont moins marqués. Le pâturage a un effet sur la couleur de la viande (qui est plus sombre) et son $\mathrm{pH}$ (plus 
élevé). Les viandes ont une flaveur plus soutenue (plus pastorale selon les jurys de dégustateurs), qui se maintient pendant près de 3 mois en cas de changement de ration. Elles sont également plus riches en acide linoléique, issu de l'herbe ingérée. L'apport naturel d'antioxydants est suffisant pour assurer une protection efficace des acides gras déposés dans les muscles. La relation entre le mode d'alimentation et la tendreté de la viande est, elle, plus controversée. Elle est très influencée par l'âge des animaux et la teneur en lipides intramusculaires, et donc par le type racial.

Ces éléments associant composition de la ration fourragère et qualité des produits animaux constituent des bases pour l'élaboration des cahiers des charges des Appellations d'origine contrôlée (AOC) ou des différents signes de qualité, telles les Indications géographiques protégées (IGP). Ces cahiers des charges valorisent aussi l'image positive accordée par les consommateurs aux produits animaux issus des prairies et du pâturage. Hauwuy et al. (2006) ont montré que ces systèmes de production contribuaient au maintien d'une agriculture performante, en région de montagne ou dans les zones périurbaines. Ainsi, la stratégie fourragère, intégrant les recommandations des cahiers, est partie prenante de la démarche et du développement des filières de production. Cela souligne l'importance de cette fonction de la prairie.

\section{Conclusion}

Cet article a souligné l'importance en France des surfaces agricoles occupées par les prairies et les cultures fourragères. Des changements significatifs se sont produits sur les surfaces et leur répartition géographique. Les cheptels animaux ont également connu des variations importantes d'effectifs au cours des dernières décennies, avec une diminution du cheptel laitier, compensé par une forte croissance du troupeau allaitant, conduisant à une stabilité globale des effectifs herbivores, mais à une évolution et une spécialisation des régions herbagères et d'élevage herbivore.

L'analyse des fonctions de production souligne le rôle des prairies dans la performance économique des exploitations d'élevage herbivore avec une préoccupation croissante liée au travail et à son organisation et indirectement à la performance des industries agroalimentaires. Elle souligne également l'importance de la qualité des produits pour la vitalité de ce secteur économique. Les prairies influençant la composition des produits laitiers et des viandes et leur qualité organoleptique et contribuant positivement à leur image, sont alors prises en compte dans les cahiers des charges de nombreuses IGP et AOC.

\section{Références}

Adler PB, Raff DA, Lauenroth WK. The effect of grazing on the spatial heterogeneity of vegetation. Oecologia $2001 ; 128: 465-79$.

Boitel A. Herbages et prairies naturelles. Paris : Firmin-Didot et Cie, 1887.

Coulon JB. Herbe et qualités des produits ani maux. Paris: Communication à l'Académie d'Agriculture, 2006

Coulon JB, Priolo A. La qualité sensorielle des produits laitiers et de la viande dépend des fourrages consommés par les animaux. INRA Prod Anim 2002 ; 15 : 333-42.

Cournut S, Dedieu B. Simplification des conduites d'élevage en bovins laitiers. Cah Agric $2005 ; 14: 541-7$.

Dedieu B, Serviere G, Madelrieux S, Dobremez L, Cournut S. Comment appréhender conjointement les changements techniques et les changements du travail en élevage ? Cah Agric 2006 ; 15 506-13. doi : 10.1684/agr.2006.0028.
Delhoume JP. Une source d'histoire rurale à l'épreuve de la critique: les états des fonds limousins (XVIIle siècle). Archives en Limousin $2004 ; 23: 20-6$.

Gaborit P, Raynal-Ljutivac K, Laurent A, Chabosseau JM, Rouel J, Chilliard Y. Flavour of goat milk and cheeses according to feeding: alfalfa hay or maize silage with oleic sunflower or linseed oil supplementation. In : Durand JL Emile JC, Huyghe C, Lemaire G, eds. Multifonction grasslands: quality forages, animal products and landscapes ". Grassland Science in Europe 2002 ; 7: 562-3.

Gilbert M. Traité sur les prairies artificielles. Paris : Société Royale d'Agriculture, 1787.

Hauwuy A, Delattre F, Roybin D, Coulon JB. Conséquences de la présence de filières fromagères bénéficiant d'une Indication Géographique sur l'activité agricole des zones considérées: I'exemple des Alpes du Nord. INRA Prod Anim 2006; 19 : 371-9.

Hnatyszyn M. Intensification fourragère au Pays d'Auge. Fourrages 1975 ; 63: 23-33.

Huyghe C, Bournoville R, Couteaudier $Y$, et al. Prairies et cultures fourragères en France. entre logiques de production et enjeux environnementaux. Versailles : Inra éditions, 2005.

Huyghe C, Litrico I, Peeters A, Elsaesser M. Conventional and organic farming of grasslands and stock rearing: trends in European markets and challenges for forage breeders. Congrès Eucarpia, Section Forage crops and amenity species. Perugia, Italie, 4-7 septembre 2006.

Le Gall A, Faverdin $P$, Thomet $P$, Vérité R. Le pâturage en Nouvelle-Zélande : des idées pour les régions arrosées d'Europe. Fourrages $2001 ; 166: 137-63$.

Lemery B, Ingrand S, Dedieu B, Degrange B. Agir en situation d'incertitude: le cas des éleveurs de bovins allaitants. Economie Rurale $2005 ; 288: 57-69$

Loucougaray G, Bonis A, Bouzillé JB. Effects of grazing by horses and/or cattle on the diversity of coastal grasslands in western France. Biological Conservation 2004 ; 116 : 59-71.

Moriceau JM. Histoire et géographie de l'élevage français, du Moyen-Âge à la Révolution. Paris : Fayard, 2005.

Opti'Pâture. Quand le pâturage est un art de vivre. Confolens: Chambre d'Agriculture de Charente, 2007.

Querret MH. De I'amélioration des prairies naturelles de la Basse-Bretagne et de la fabrication et de la conservation des fourrages. Brest : Editions Le Blois, 1845.

Tilman D, Hill J, Lehman C. Carbon-negative biofuels from low-input high-diversity grassland biomass. Science 2006 ; 314 : 1598-600. 